\title{
Social determinants of prostate cancer in the Caribbean: a systematic review and meta-analysis
}

\author{
Catherine R. Brown ${ }^{1 *}$ D, lan Hambleton ${ }^{1}$, Shawn M. Hercules ${ }^{1,2}$, Nigel Unwin ${ }^{1,3}$, Madhuvanti M. Murphy ${ }^{4}$, \\ E. Nigel Harris ${ }^{5}$, Rainford Wilks ${ }^{5}$, Marlene MacLeish ${ }^{6}$, Louis Sullivan ${ }^{6}$, Natasha Sobers-Grannum ${ }^{4}$ and The U.S. \\ Caribbean Alliance for Health Disparities Research Group (USCAHDR)
}

\begin{abstract}
Background: Prostate cancer remains the leading cause of cancer deaths among Caribbean men. However, little data exists on the influence of social factors on prostate cancer in the Caribbean setting. This article supports the 2011 Rio Political Declaration on addressing health inequalities by presenting a systematic review of evidence on the role of social determinants on prostate cancer in Caribbean men. It aims to determine the distribution, by known social determinants of health, of the frequency and adverse outcomes of prostate cancer among Caribbean populations.

Methods: Observational studies reporting an association between a social determinant and prostate cancer frequency and outcomes were sought in MEDLINE, EMBASE, SCIELO, CINAHL, CUMED, LILACS, and IBECS databases. Fourteen social determinants and 7 prostate cancer endpoints were chosen, providing 98 possible relationship groups exploring the role of social determinants on prostate cancer. Observational studies with $>50$ participants conducted in Caribbean territories between 2004 and 2016 were eligible. The review was conducted according to STROBE and PRISMA guidelines. Random-effects meta-analyses were performed.

Results: From 843 potentially relevant citations, 13 articles from 9 studies were included. From these included studies, 24 relationships were reported looking at 11 distinct relationship groups, leaving 90 relationship groups (92\% of all relationship groups) unexplored. Study heterogeneity and risk of bias restricted results to a narrative synthesis in most instances. Meta-analyses showed more diagnosed prostate cancer among men with less formal education ( $n=2$ studies, OR 1.60,95\%Cl 1.18-2.19) and among men who were married ( $n=3$ studies, OR 1.54, $95 \% \mathrm{Cl} 1.22-1.95)$.

Conclusions: This review highlights limited evidence for a higher occurrence of diagnosed prostate cancer among Caribbean men with lower levels of education and among men who are married. The role of social determinants on prostate cancer among Caribbean men remains poorly understood. Improvements in study quantity and quality, and reduced variability in outcomes and reporting are needed. This report represents the current evidence, and provides a roadmap to future research priorities for a better understanding of Caribbean prostate cancer inequalities.
\end{abstract}

Keywords: Disparity, Inequality, Social determinants, Prostate cancer, Systematic review, Caribbean

\footnotetext{
* Correspondence: catherine.brown@cavehill.uwi.edu

${ }^{1}$ George Alleyne Chronic Disease Research Centre, Caribbean Institute for Health Research, The University of the West Indies, Bridgetown, Barbados Full list of author information is available at the end of the article
}

(c) The Author(s). 2018 Open Access This article is distributed under the terms of the Creative Commons Attribution 4.0 International License (http://creativecommons.org/licenses/by/4.0/), which permits unrestricted use, distribution, and reproduction in any medium, provided you give appropriate credit to the original author(s) and the source, provide a link to the Creative Commons license, and indicate if changes were made. The Creative Commons Public Domain Dedication waiver (http://creativecommons.org/publicdomain/zero/1.0/) applies to the data made available in this article, unless otherwise stated. 


\section{Background}

In 2015, prostate cancer accounted for about one-quarter of all male cancer deaths in the Caribbean, making it the leading cause of male cancer deaths and the third leading cause of male deaths overall [1]. The age-standardized mortality rate from prostate cancer among Caribbean men was estimated to be 50 per 100,000 in 2015, over twice the mortality seen in the USA and UK $[1,2]$. Caribbean rates have increased by nearly $40 \%$ since 1990, in contrast to the decrease seen among many industrialised countries $[1,2]$. Prostate cancer occurrence increases after age 40 and is more common among African-Americans and men with particular germline mutations [3, 4]. Evidence on the role of other factors - such as diet, hormone levels, obesity and social determinants - on prostate cancer onset and progression remains less conclusive [4].

Despite the overall high mortality from prostate cancer in the Caribbean, little is known about whether prostate cancer and its outcomes vary within Caribbean populations. The 2007 Port of Spain Declaration was affirmed by Caribbean Commonwealth Heads of Government to reduce the burden caused by noncommunicable diseases (NCDs) [5]. Describing Caribbean NCD variability and associated social drivers is relevant in guiding public health policy in reducing NCDs. This is underscored by the 2011 Rio Political Declaration through which countries have committed to monitor and address health inequities, and the World Health Organization (WHO) Commission on the Social Determinants of Health $(\mathrm{CSDH})$ has emphasized the importance of research to accommodate these objectives [6, 7].

Research exploring social inequalities among men with prostate cancer in the UK and USA offers evidence for the influence of ethnicity, socioeconomic position (SEP) and occupational exposures [8-14]. However, the social determinants of prostate cancer among Caribbean populations have yet to be reviewed systematically. The aim of this review is therefore to determine the distribution, by known social determinants of health, of the incidence, prevalence, and adverse outcomes of prostate cancer among populations living in the Caribbean. This process is guided by the analytical framework used to examine the social determinants of specific conditions by the WHO CSDH [15].

\section{Methods}

A study protocol (see Additional file 1) provides the full methodology details. The methods were guided by a previous systematic review of social determinants of diabetes [16] and an initial scoping review of prostate cancer.

\section{Eligibility criteria}

Observational studies from 32 Caribbean territories were sought, which reported at least one relationship between a social determinant and prostate cancer frequency (incidence, prevalence) or prostate cancer outcome (cancer stage, grade, recurrence, survival, and mortality). Articles written in the four official Caribbean languages (English, Spanish, French, and Dutch) were included. Study samples of any age were included, and were sampled from the general population or from healthcare facilities. Studies including less than 50 men were excluded as unlikely to be fully representative of the general population. Guided by the PRISMA statement for transparent reporting of systematic reviews and meta-analyses with a focus on health equity, which recommends the "PROGRESS" checklist, the following social determinants were used: place of residence, race or ethnicity, occupation, gender, religion, education, socio-economic position (SEP), and social capital [17]. Reports published between January 2004 and December 2014 were originally sought for inclusion, with a recent review update to also include reports published in 2015 and 2016. This study has taken place within the context of a major review of regional and national policy responses in the Caribbean to chronic NCDs [18]; the review period was selected as relevant to the current situation and able to inform policy response.

\section{Search strategy, study selection, data abstraction}

MEDLINE (via Pubmed), EMBASE (via Ovid), SciELO (via SciELO), CINAHL (via EBSCO), and CUMED, LILACS, and IBECS (via WHO Virtual Health Library) databases were searched [19-23] using Endnote as the reference management software [24]. The final search was conducted in July 2017. The search strategies used are detailed Additional file 2.

Studies were selected and data was abstracted independently by two reviewers (SH, CB). Titles and abstracts were screened to first identify articles that were potentially relevant. Then, full-texts of these potentially relevant articles were screened to identify articles for inclusion. An electronic data abstraction form was created (see Additional file 1) using the REDCap software [25], and its content guided by the STROBE statement on strengthening the reporting of observational studies in epidemiology and the PRISMA-Equity statement [26, 27]. Inconsistent screening and abstraction results were reviewed by an independent third party (NSG).

\section{Risk of bias assessment}

STROBE and Cochrane guidelines (see Additional file 1) were jointly used to create a risk of bias was tool which was used to assess bias at the relationship level [26, 28]. Five domains were assessed:

- Confounding (ie: might a relationship be affected by an unmeasured confounder?)

- Participant selection (ie: is the sample representative of the target population?) 
- Missing data (ie: is the data reasonably complete?)

- Outcome measurement (ie: is a social determinant/ disease endpoint appropriately measured?)

- Selective reporting (ie: is a relationship selectively reported?).

Relationships and articles were classified as having serious, moderate, low, or unclear risk of bias. Two reviewers (CB, NSG) made an independent judgement on the overall risk of bias of each included relationship and article, with any discrepancies resolved through discussion.

\section{Synthesis of results}

The review was planned as a narrative synthesis, with meta-analysis of quantitative evidence restricted to relationships reported by $\geq 2$ studies classified as having low or moderate risk of bias. Key study details are presented, followed by a description of each association between a social determinant and either a measure of disease frequency or a measure of disease outcome (with each association being termed an inequality relationship'). An evidence gap map (Fig. 2) was used to summarize the number and type of inequality relationships [29]. Random-effects meta-analyses were performed in recognition of the anticipated heterogeneity between studies. Relationships eligible for meta-analysis described cancer frequency and were summarised using odds ratios. Sensitivity analyses included studies classified as having high/ unclear risk of bias. All quantitative summaries were performed using Stata statistical software (release 14, College Station, TX: StataCorp LP).

\section{Results}

Summary of included studies

Figure 1 presents a flowchart of articles identified, excluded, and included. From 843 identified articles, 13

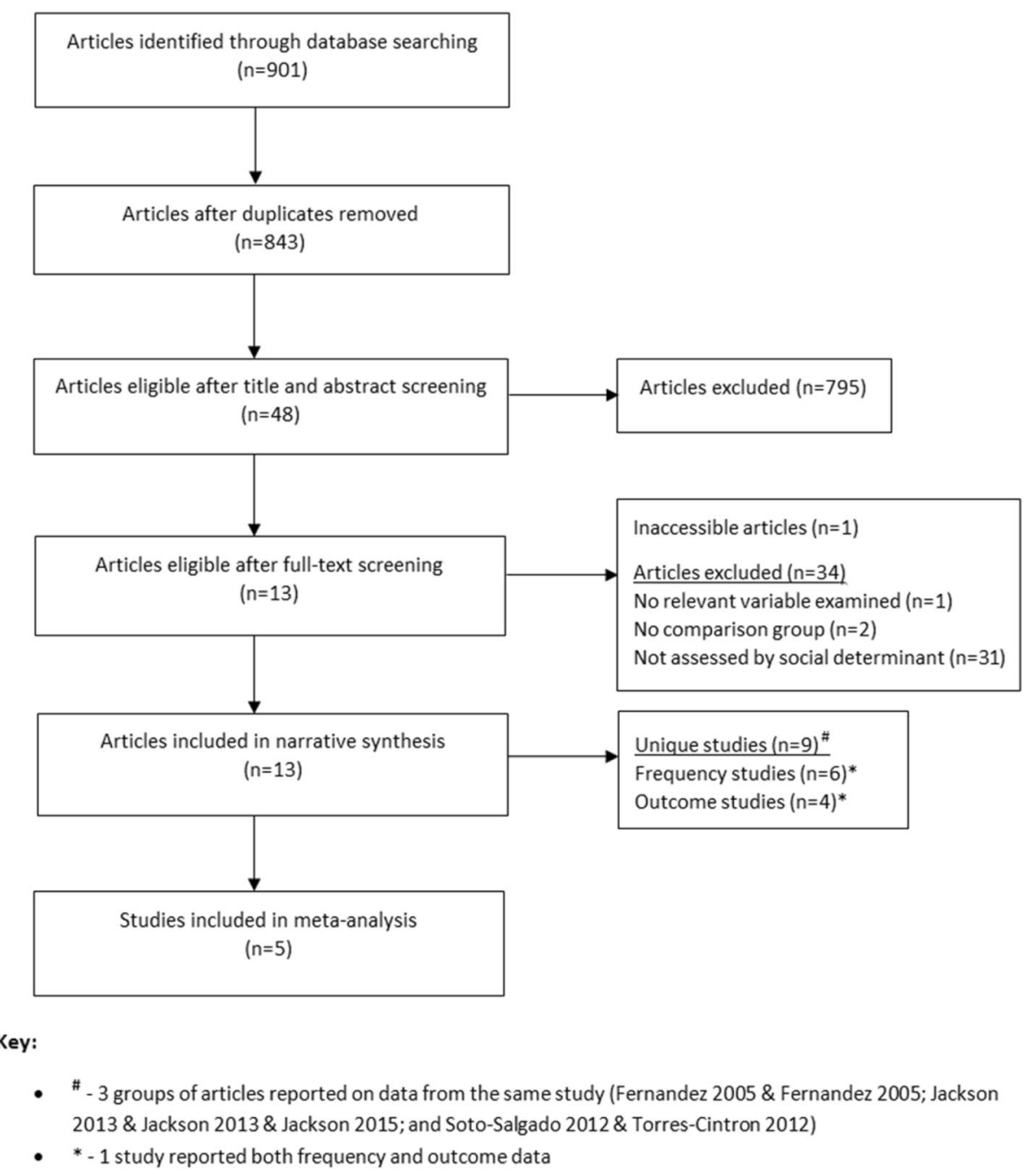

Fig. 1 Flowchart of search strategy and article selection 
articles reporting data from 9 unique studies were eligible for inclusion.

Table 1 describes characteristics of the 13 included articles; all studies included 1 or more social determinant stratifications. Seven social determinants were examined by these articles. Of these 13 articles, 10 reported on prostate cancer frequency and 4 reported on prostate cancer outcomes. The studies were conducted in English-speaking (Barbados, Jamaica, Trinidad and Tobago); French-speaking (Guadeloupe) and Spanish-speaking (Cuba, Puerto Rico) Caribbean countries. Most articles reported on populations in Cuba, Jamaica, and Puerto Rico ( $n=4$ for each). Figure 2 summarizes the inequality relationships reported in the included articles.

There were 24 inequality relationships reported: 18 on prostate cancer frequency and 6 on prostate cancer outcomes. When articles reporting data from the same study are removed, the number of inequality relationships falls to 17: 12 on frequency and 5 on outcomes. There is a crucial evidence gap on the effects of social determinants on prostate cancer among Caribbean men. With 14 social determinants and 7 review outcomes, there were 98 unique inequality relationship groups that could have been reported. Just 8 (8\%) of these relationship groups were reported by the 13 included articles, leaving 90 (92\%) relationship groups without an evidence base.

\section{Risk of bias of included studies}

The risk of bias assigned to each of the 24 social determinant relationships is presented in Table 2. Of the 13 articles, 1 was classified as having low risk of bias, 9 as having moderate risk of bias, 1 as having serious risk of bias, and 1 as having unclear risk of bias. Figure 3 details the proportion of relationship classifications within each of the 5 risk of bias domains. Overall, lack of adjustment for confounding was the main contributor to an increased risk of bias, followed by non-disclosure or inadequate handling of missing data.

\section{Summary of included inequality relationships Prostate cancer frequency}

There were 18 inequality relationships examining the frequency of prostate cancer, reported by 10 articles across 5 social determinants: education $(n=8)$, ethnicity $(n=2)$, marital status $(n=4)$, occupation $(n=2)$, and SEP $(n=2)$ [30-39]. Prostate cancer frequency was defined as the number of cases by 8 articles and incidence rate by 2 articles $[34,38]$.

Six studies (8 articles) examined the association of prostate cancer frequency and education, 5 of which reported an increased frequency of prostate cancer among men with less formal education [30-33, 35-37, 39]. All studies used a case-control design, and relationships originated from Cuba $(n=2)$, Jamaica $(n=3)$, Barbados $(n=1)$, Guadeloupe $(n=1)$, and Trinidad and Tobago $(n=1)$. Seven relationships were of moderate risk of bias, while the single Guadeloupe relationship was of high risk of bias. Figure 4 presents a meta-analysis of the relationship between education and prostate cancer frequency; multiple articles reporting data from the same study were not included. Using studies classified as having low or moderate risk of bias [31, 32] and stratifying education as "primary or less" or "secondary or more", results indicate that men with primary education or less were more likely to have had prostate cancer (OR 1.60, 95\%CI 1.18-2.19). In a sensitivity analysis including 1 additional serious-risk study [37], the direction of effect remained but the pooled odds ratio reduced in size (OR 1.35, 95\% CI 1.07-1.70).

Four articles from 3 studies examined the age-adjusted association of prostate cancer frequency and marital status, showing higher prostate cancer frequency among married men [30, 31, 33, 36]. All studies used a case-control design and relationships originated in Barbados $(n=1)$, Cuba $(n=2)$, and Trinidad and Tobago $(n=1)$. Three relationships were classified as moderate risk of bias, while the Trinidad study was classified as having low risk of bias. Figure 5 presents the meta-analysis of the relationship between prostate cancer and marital status; multiple articles reporting data from the same study were not included. Stratifying marital status as "ever married" or "never married", married men were more likely to have had prostate cancer (OR $1.54,95 \%$ CI $1.22-1.95)[31,33,36]$.

Two articles from 1 Cuban case-control study examined the age-adjusted association of prostate cancer frequency and ethnicity, reporting that Black Cuban men were more likely to have prostate cancer than White Cuban men (OR 1.3, CI 0.9-1.9; $p=0.05$ ) [30, 31]. These relationships were classified as having moderate risk of bias. Two articles from Cuba and Barbados examined the relationship between prostate cancer frequency and occupation, neither reporting an association [30, 33]. Both relationships were of moderate risk of bias. Two articles from 1 Puerto Rican study examined the association between prostate cancer frequency and SEP $[34,38]$. SEP was defined by 8 residential area level indicators and both articles reported higher rates of prostate cancer among men with higher SEP (SEP5 (highest)/ SEP1 (lowest) ratio 1.12, 95\% CI 1.04-1.21).

\section{Prostate cancer outcomes}

There were 6 inequality relationships reporting on prostate cancer outcomes, reported by 5 articles across 3 social determinants: education $(n=1)$, residence $(n=3)$, and SEP $(n=2)$ [34, 38, 40-42]. Mortality was the only outcome reported and studies were cohort, cross-sectional and registry-based designs. Studies originated from Puerto Rico 
Brown et al. BMC Public Health (2018) 18:900

Page 5 of 14

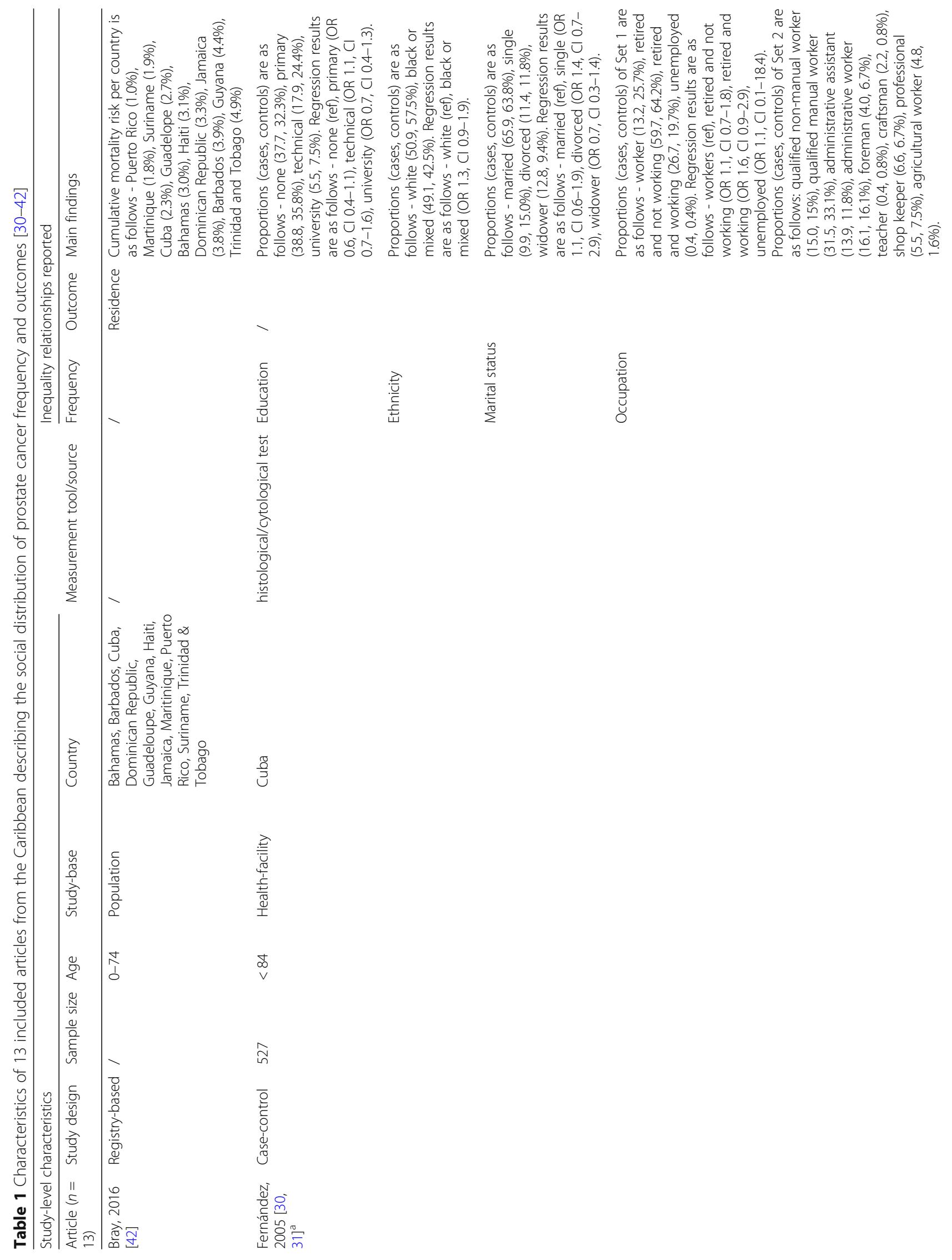




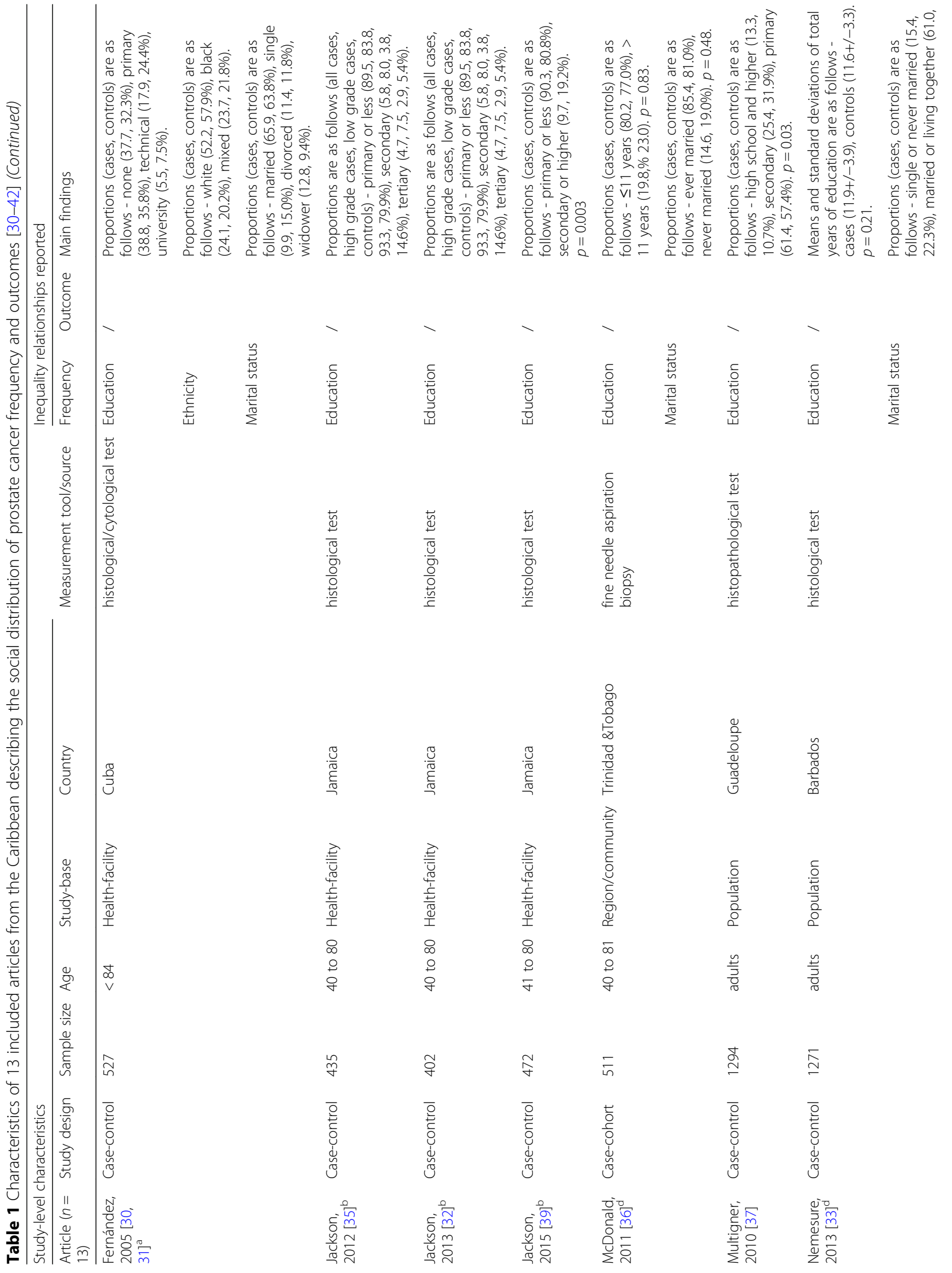




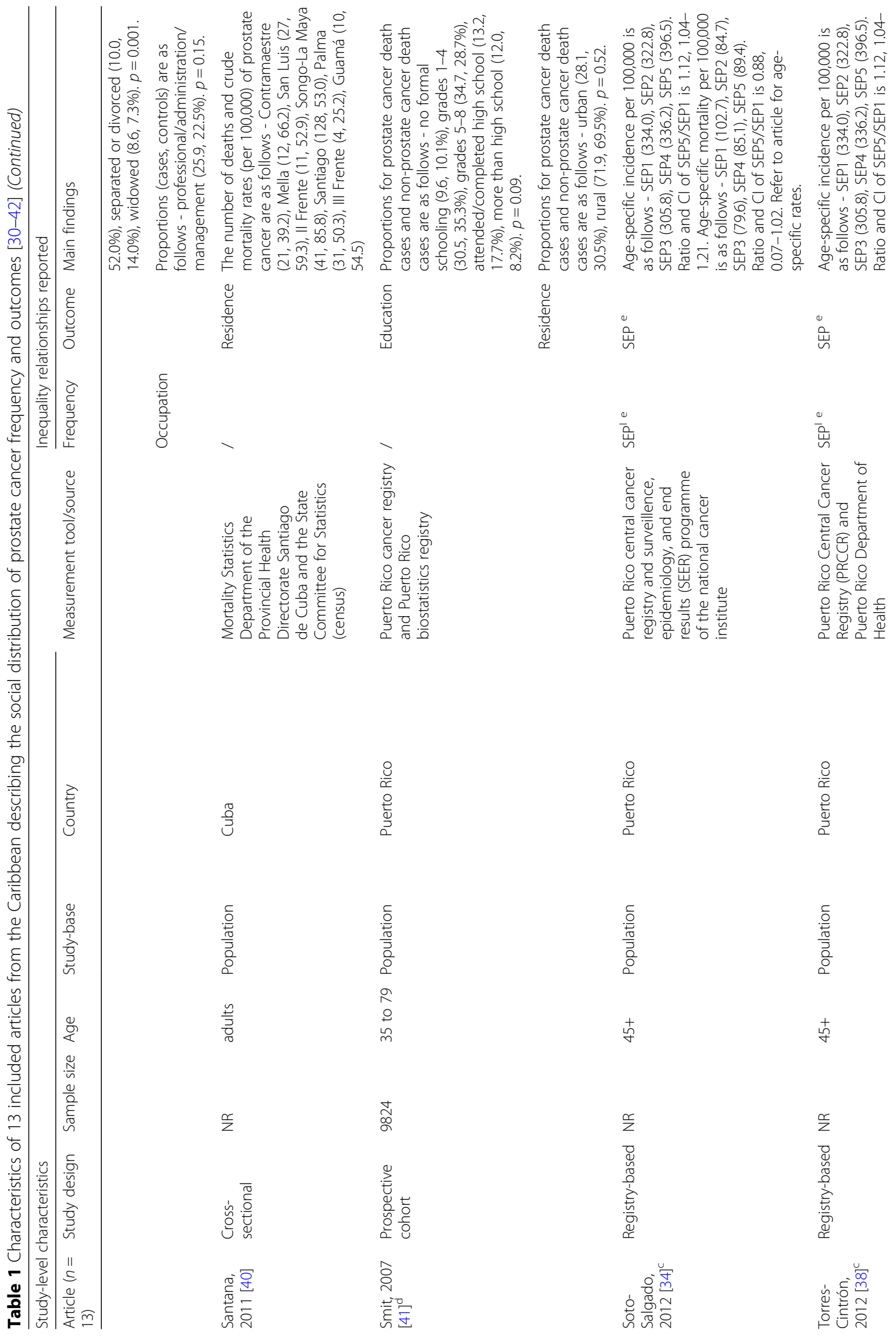




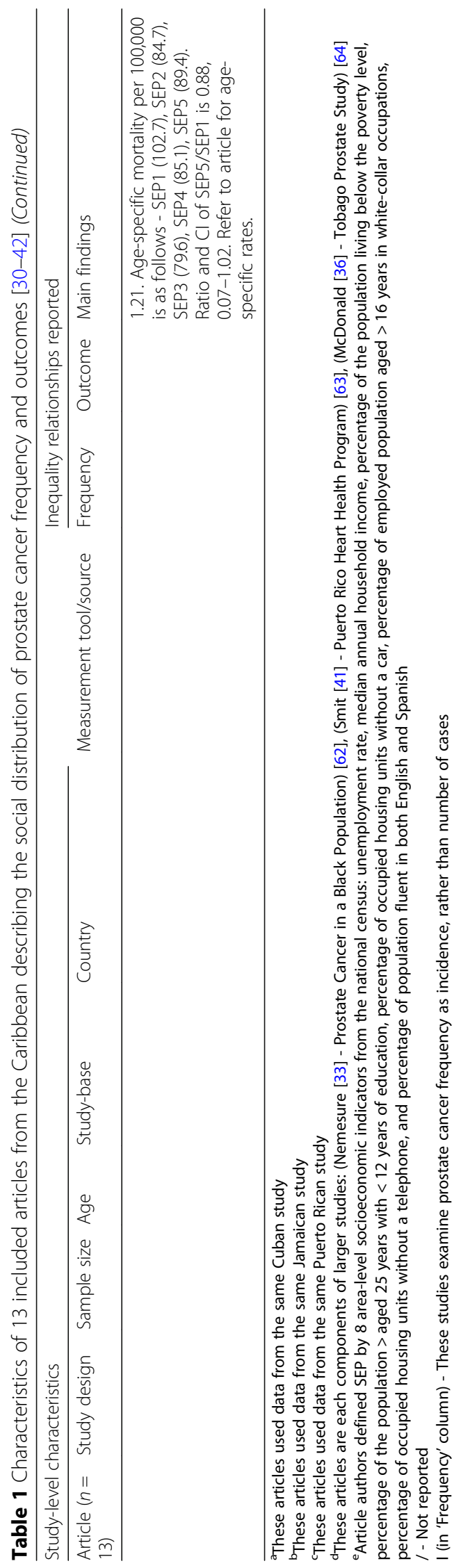




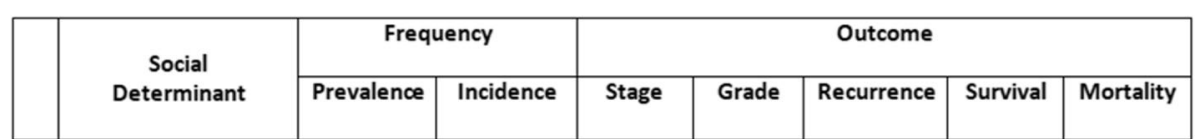

\begin{tabular}{|l|r|r|l|l|l|l|l|l|}
\hline $\mathbf{P}$ & Residence & & & & & & & 3 MIX \\
\hline \multirow{2}{*}{$\mathbf{R}$} & Ethnicity or Race & $1 \mathrm{AD}$ & & & & & & \\
\cline { 2 - 9 } & Language & & & & & & & \\
\hline & Culture & & & & & & & \\
\hline
\end{tabular}

\begin{tabular}{|l|r|r|r|r|r|r|r|r|}
\hline O & Occupation & 2 NIL & & & & & & \\
\hline G & Gender & & & & & & & \\
\hline R & Religion & & & & & & & \\
\hline E & Education & $5 \mathrm{NEG}$ & & & & & & 1 NIL \\
\hline S & $\begin{array}{r}\text { SEP } \\
\text { Income }\end{array}$ & & 1 POS & & & & & 1 NEG \\
\hline
\end{tabular}

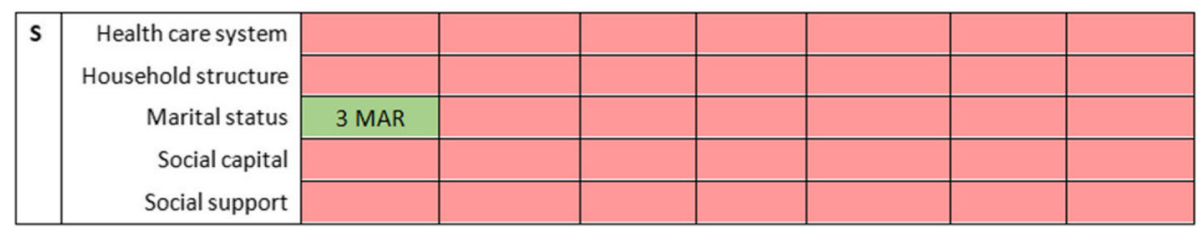

Key:

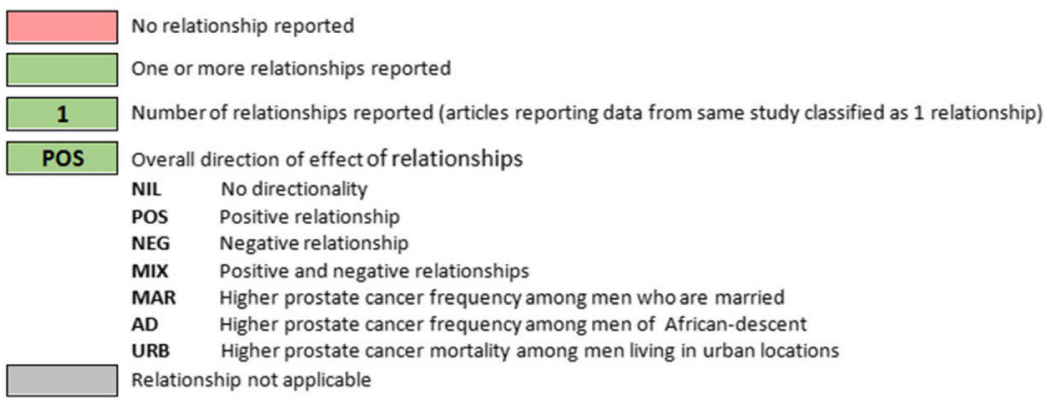

Fig. 2 Summary of 17 unique relationships among 13 included articles [30-42]

$(n=4)$ and Cuba $(n=1)$, with the remaining study examining 12 Caribbean territories collectively. All relationships were classified as moderate risk of bias, except for the single Cuban study examining residence which was classified as serious risk of bias and the Caribbean-wide study examining residence which was classified as unclear risk of bias.

The single study examining education and mortality (Puerto Rico) reported no association [41]. Three studies examining mortality and area of residence offered limited information [40-42]. The Cuban study did not differenciate rural/urban divides, while the Puerto Rican study reported no difference in mortality in urban versus rural locations. The Caribbean-wide study did not formally assess mortality differences in urban versus rural settings, but did list mortality rates by country. Barbados (3.9\%), Guyana (4.4\%), and Trinidad and Tobago (4.9\%) were reported to have the highest cumulative mortality risks, while Puerto Rico had the lowest risk of 1.0\% [42].
Two articles from 1 Cuban study examined the association between mortality and SEP, reporting that men with lower SEPs had higher age-adjusted prostate cancer mortality (SEP5 (highest)/SEP1 (lowest) ratio 0.88, 95\% CI 0.07-1.02) [34, 38].

\section{Discussion}

\section{Summary of evidence}

This systematic review has examined the extent of evidence on the influence of social determinants of health on prostate cancer frequency and adverse outcomes in the Caribbean. Thirteen articles from 9 separate studies were included. With 14 possible social determinants and 7 chosen prostate cancer endpoints, there were 98 possible ways (relationship groups) of exploring the role of social determinants on prostate cancer. From the included studies, 24 relationships were reported looking at 
Table 2 Risk of bias assessments among 24 relationships from 13 included articles [30-42]

\begin{tabular}{|c|c|c|c|c|c|c|c|c|}
\hline \multirow[t]{2}{*}{ Article $(n=13)$} & \multicolumn{2}{|c|}{ Relationship $(n=24)$} & \multicolumn{6}{|l|}{ Bias domain } \\
\hline & Endpoint & Social determinant & Confounding & $\begin{array}{l}\text { Participant } \\
\text { selection }\end{array}$ & Missing data & $\begin{array}{l}\text { Measurement } \\
\text { of outcomes }\end{array}$ & $\begin{array}{l}\text { Selective } \\
\text { reporting }\end{array}$ & Overall \\
\hline Bray, 2016 [42] & Outcome & Residence & Moderate & Unclear & Unclear & Low & Low & Unclear \\
\hline \multirow[t]{4}{*}{ Fernández, $2005[30,31]^{\mathrm{a}}$} & Frequency & Education & Moderate & Low & Low & Low & Low & Moderate \\
\hline & Frequency & Ethnicity & Moderate & Low & Low & Low & Low & Moderate \\
\hline & Frequency & Marital Status & Moderate & Low & Low & Low & Low & Moderate \\
\hline & Frequency & Occupation & Moderate & Low & Low & Low & Serious & Moderate \\
\hline \multirow[t]{3}{*}{ Fernández, $2005[30,31]^{a}$} & Frequency & Education & Moderate & Low & Low & Low & Low & Moderate \\
\hline & Frequency & Ethnicity & Moderate & Low & Low & Low & Low & Moderate \\
\hline & Frequency & Marital Status & Moderate & Low & Low & Low & Low & Moderate \\
\hline Jackson, $2012[35]^{\mathrm{b}}$ & Frequency & Education & Moderate & Low & Unclear & Low & Low & Moderate \\
\hline Jackson, $2013[32]^{\mathrm{b}}$ & Frequency & Education & Moderate & Low & Serious & Low & Low & Moderate \\
\hline Jackson, 2015 [39] ${ }^{\mathrm{b}}$ & Frequency & Education & Moderate & Low & Serious & Low & Low & Moderate \\
\hline \multirow[t]{2}{*}{ McDonald, $2011[36]^{d}$} & Frequency & Education & Low & Low & Low & Low & Low & Low \\
\hline & Frequency & Marital Status & Low & Low & Low & Low & Low & Low \\
\hline Multigner, 2010 [37] & Frequency & Education & Serious & Serious & Low & Low & Low & Serious \\
\hline \multirow[t]{3}{*}{ Nemesure, $2013[33]^{d}$} & Frequency & Education & Moderate & Low & Serious & Low & Low & Moderate \\
\hline & Frequency & Marital Status & Moderate & Low & Serious & Low & Low & Moderate \\
\hline & Frequency & Occupation & Moderate & Low & Serious & Low & Low & Moderate \\
\hline Santana, 2011 [40] & Outcome & Residence & Serious & Low & Unclear & Low & Low & Serious \\
\hline \multirow[t]{2}{*}{ Smit, $2007[41]^{d}$} & Outcome & Education & Moderate & Low & Low & Low & Low & Moderate \\
\hline & Outcome & Residence & Moderate & Low & Low & Low & Low & Moderate \\
\hline \multirow[t]{2}{*}{ Soto-Salgado, 2012 [34] ${ }^{c}$} & Frequency & SEP & Moderate & Low & Unclear & Low & Low & Moderate \\
\hline & Outcome & SEP & Moderate & Low & Unclear & Low & Low & Moderate \\
\hline \multirow[t]{2}{*}{ Torres-Cintrón, $2012[38]^{c}$} & Frequency & SEP & Moderate & Low & Unclear & Low & Low & Moderate \\
\hline & Outcome & SEP & Moderate & Low & Unclear & Low & Low & Moderate \\
\hline
\end{tabular}

${ }^{a}$ These articles used data from the same Cuban study

${ }^{\mathrm{b}}$ These articles used data from the same Jamaican study

'These articles used data from the same Puerto Rican study

${ }^{\mathrm{d}}$ These articles are each components of larger studies: (Nemesure [33] - Prostate Cancer in a Black Population) [62], (Smit [41] - Puerto Rico Heart Health Program) [63], (McDonald [36] - Tobago Prostate Study) [64]

8 distinct relationship groups, leaving 90 relationship groups (92\% of all groups) without an evidence base.

Most articles were classified as having moderate risk of bias, mostly because of failures to adjust for important potential confounders, which limited interpretation. A key consideration for social determinant studies is the recognition of interrelationships among the social determinants themselves. For instance, ethnicity often contributes to our understanding of inequalities between population subgroups. Using an international example, African Americans are often disadvantaged compared to Caucasian Americans in terms of education, occupation, and income; with each of these social determinants associated strongly with access to healthcare and later health effects [43].

In this review, prostate cancer occurrence was consistently higher in men with lower levels of education, which conflicts with some international evidence [44-46]. In a US study, for example, higher education was associated in all ethnic groups with a higher prostate cancer incidence, attributed partly to greater use of health and screening services [45]. Inequalities in screening uptake can be influenced by differences in health-seeking behaviour or access to healthcare provision $[13,34,44]$. For instance, increased screening by more affluent social groups is reflected in our finding that Caribbean men in higher SEPs had a higher incidence of prostate cancer [34, 38]. A more recent Caribbean study supports this notion of SEP inequalities - this time through income inequalities - with screening for prostate cancer reported to be higher among Dominican Republicans with health insurance coverage [47]. Our conflicting finding for education may reflect the dynamics of different healthcare systems between Puerto Rico (SEP study) and countries examining education (Cuba, Jamaica, 


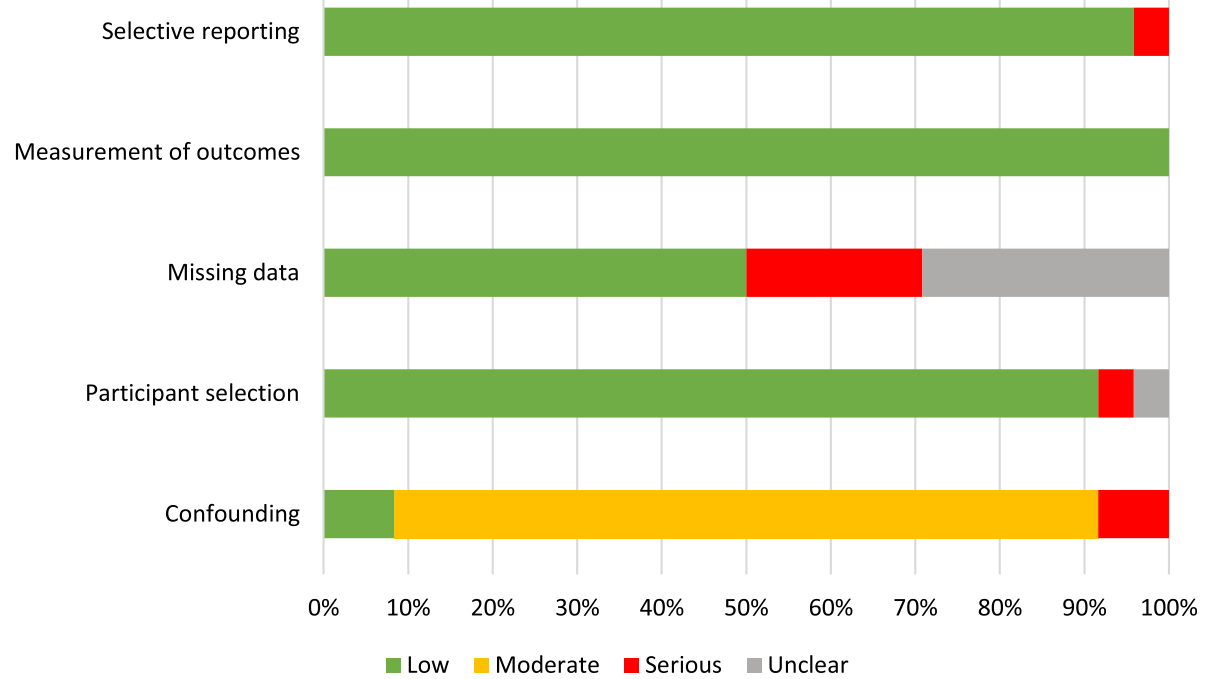

Fig. 3 Proportion of risk of bias classifications of the 24 relationships across the 5 domains [30-42]

Barbados, Guadeloupe, Trinidad and Tobago); the interplay of proxies defining SEP; or perhaps a failure of the included studies to fully explore interrelationships between competing social determinants (such as education and ethnicity, or education and social support).

Similar to other settings [48, 49], marriage was associated with a higher reported occurrence of prostate cancer in Caribbean men $[30,31,33,36]$. The social support extended by marriage is thought to promote health-seeking behaviour, leading to a greater chance of diagnosis $[50,51]$. Without this social support, health-seeking reluctance leads to delayed diagnosis and a higher risk of adverse outcomes.
On the other hand, a growing body of evidence explains that men with fewer sexual partners and subsequent lower rates of venereal disease, as well as men with a higher ejaculation frequency - both likely conditions of a typical married life - could lower the risk of developing prostate cancer [32, 52-58]. The social consequences of marriage might therefore also include a lower prostate cancer mortality [56].

Our results highlighting an increased prostate cancer frequency among men of African descent are supported by a large body of evidence emphasizing the importance of ethnicity as a social determinant of lifestyle risk factors

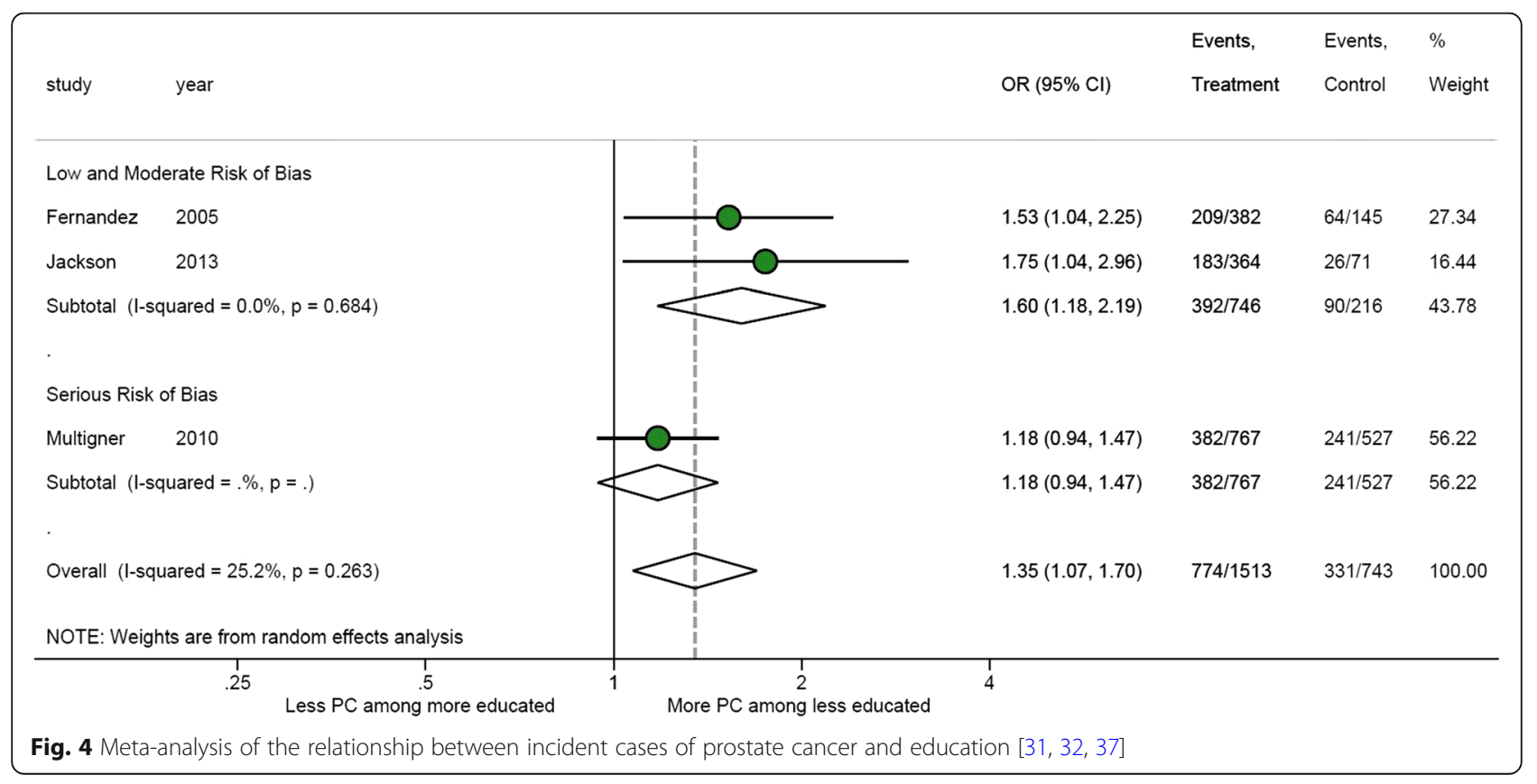




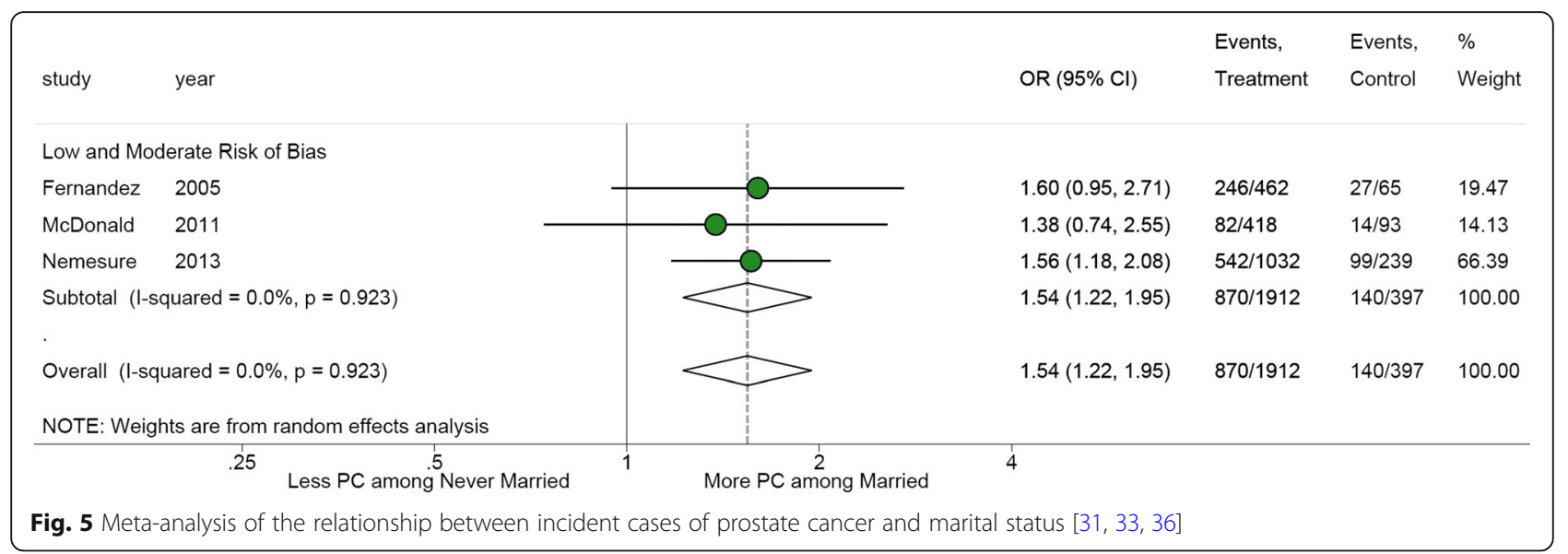

and health status $[12,34,43,45,57,58]$. However, a biological component may also be at play. Genotypes associated with prostate cancer incidence and prognosis, such as Steroid 5 alpha-reductase and Cytochrome P450 3A4, are more commonly seen in persons of African origin [34, $43,58,59]$. The predominance of an 'African genome' in many Caribbean populations could play a role in the regional burden of prostate cancer, and its interplay with social determinants remains an important area for further research $[34,58,59]$.

Evidence for associations between social determinants and prostate cancer outcomes is sparse. Mortality from prostate cancer was reported to be higher among men with a lower SEP [34, 38]. This may be related to reduced availability of or access to screening and other health care services, as well as reduced health literacy impacting on cancer stage at diagnosis and treatment adherence [43-45]. Notably, the Cuban study examining SEP calculated SEP using community-level measurements (see Table 1 footnote); other Caribbean settings, using individual-level SEP, may have different findings.

An important consideration when examining differences between studies from different Caribbean countries is country-level healthcare governance. Two locations of our included studies - Guadeloupe and Puerto Rico - are territories of France and the USA respectively, with the commensurate possibility of greater healthcare resources. For instance, in a recent examination of life expectancy in the Caribbean, Martinique and Guadeloupe (territories of France) had the highest Caribbean life expectancies and the largest improvements in life expectancy over 40 years [60]. However, as it applies to the included studies of this review from non-sovereign Caribbean countries [34, 37, 38, 41, 42, 61], they either showed no difference in directionality from relationships of independent Caribbean territories or their relationships were not reported by other independent Caribbean territories to allow comparison.

\section{Limitations}

This review is limited by a small number of articles eligible for inclusion $(n=13)$, particularly for prostate cancer outcomes. The Caribbean - considered as one region geographically - indeed has country-level variation in social determinants that are possibly masked by this grouping and analysis. Publication bias is an important concern as limited resources restricted grey literature searching. At the study-level, validity of results is limited by the moderate or serious risk of bias assigned to many of the included studies. Country-level information on screening and access to treatment, such as prostate-specific antigen screening rates and wait times for diagnosis or treatment, are important potential confounders that were not assessed in the individual studies.

\section{Conclusion}

This review suggests a higher occurrence of prostate cancer among Caribbean men with lower levels of education (OR 1.60, 95\%CI 1.18-2.19) and among married men (OR 1.54, 95\%CI 1.22-1.95). Statements on the role of other social determinants in the Caribbean must be tempered by a paucity and limited quality of evidence. The WHO CSDH has highlighted the role of health research in understanding health inequities, and Caribbean countries have committed to addressing these inequities [6, 7]. Although the need for more research in this area is acknowledged, this effort to improve the evidence base should include an attempt at standardizing reporting guidelines for observational studies of inequality. For systematic reviews of observational evidence, the development of a validated risk of bias assessment tools is an imperative.

\section{Additional files}

Additional file 1: Study Protocol. (DOCX 4024 kb)

Additional file 2: Search Strategies. (DOCX 16 kb) 


\section{Abbreviations}

CINAHL: Cumulative Index of Nursing and Allied Health Literature; CSDH: Commission on the Social Determinants of Health; CUMED: Cuba Medicina; EMBASE: Excerpta Medica Database; IBECS: Índice Bibliográfico Español en Ciencias de la Salud; LILACS: Latin American and Caribbean Health Sciences; MEDLINE: Medical Literature Analysis and Retrieval System Online, or MEDLARS Online; NCD: Noncommunicable disease; SciELO: Scientific Electronic Library Online; SEP: Socioeconomic Position; STROBE: Strengthening the Reporting of Observational studies in Epidemiology; USCAHDR: United States Caribbean Alliance for Health Disparities Research Group; WHO: World Health Organization

\section{Acknowledgements}

Members of the U.S. Caribbean Alliance for Health Disparities Research Group outside of the writing group are acknowledged for their support in this research: Miriam Alvarado, Nadia Bennett, Aurelian Bidulescu, Catherine R. Brown, Trevor Ferguson, Damian Francis, lan R. Hambleton, Eon Nigel Harris, Christopher Hassell, Anselm J. M. Hennis, Shawn M. Hercules, Christina Howitt, Marlene MacLeish, Madhuvanti M. Murphy, Thelma Alafia Samuels, Natasha Sobers-Grannum, Louis Sullivan (group lead, Sullivan@pemsm.com), Nigel Unwin, Rainford Wilks, Lynda Williams and Novie Younger-Coleman.

\section{Funding}

This study was fully supported by grant number U24MD006959 from the National Institute on Minority Health and Health Disparities. The funding body was not involved in the design of the study, collection, analysis, and interpretation of data, nor the writing the manuscript. The content is solely the responsibility of the authors and does not necessarily represent the official views of the National Institute on Minority Health and Health Disparities or the National Institutes of Health.

\section{Availability of data and materials}

The data that support the findings of this study are available from the databases accessed in the study, but restrictions apply to the availability of these data which were used under license for this current study, and so are not publicly available. Please see Table 1 of this manuscript for a summary of the data from each included file. Detailed data are however available from the authors upon reasonable request and with permission of the original study author.

\section{Authors' contributions}

CRB - acquisition, analysis, and interpretation of data, drafting the work, final approval of the version to be published. $\mathrm{IH}$ - conception and design of the work, analysis and interpretation of data, drafting the work, revising it critically for important intellectual content, final approval of the version to be published. SMH - acquisition, analysis, and interpretation of data, draft revisions, final approval of the version to be published. MMM - design of the work, analysis and interpretation of data, drafting the work, final approval of the version to be published. NU - conception and design of the work, interpretation of data, revising it critically for important intellectual content, final approval of the version to be published. $\mathrm{CH}$ - analysis and interpretation of data, drafting the work, revising it critically for important intellectual content, final approval of the version to be published. ENH - conception and design of the work, revising it critically for important intellectual content, final approval of the version to be published. RW - conception and design of the work, revising it critically for important intellectual content, final approval of the version to be published. MM - conception and design of the work, revising it critically for important intellectual content, final approval of the version to be published. LS - conception and design of the work, revising it critically for important intellectual content, final approval of the version to be published. NSG - conception and design of the work, acquisition, analysis and interpretation of data, drafting the work, revising it critically for important intellectual content, final approval of the version to be published. All authors read and approved the final manuscript.

\section{Ethics approval and consent to participate} Not applicable.

\section{Consent for publication}

Not applicable.

\section{Competing interests}

The authors declare that they have no competing interests.

\section{Publisher's Note}

Springer Nature remains neutral with regard to jurisdictional claims in published maps and institutional affiliations.

\section{Author details}

${ }^{1}$ George Alleyne Chronic Disease Research Centre, Caribbean Institute for Health Research, The University of the West Indies, Bridgetown, Barbados. ${ }^{2}$ Department of Biology, McMaster University, Hamilton, ON, Canada. ${ }^{3}$ MRC Epidemiology Unit, University of Cambridge, Cambridge, England. ${ }^{4}$ Faculty of Medical Sciences, The University of the West Indies, Cave Hill, Barbados. ${ }^{5}$ The University of the West Indies, Kingston, Jamaica. ${ }^{6}$ The Sullivan Alliance, Alexandria, VA, USA.

Received: 17 April 2018 Accepted: 11 June 2018

Published online: 20 July 2018

\section{References}

1. Lozano R, Naghavi M, Foreman K, Lim S, Shibuya K, Aboyans V, et al. Global and regional mortality from 235 causes of death for 20 age groups in 1990 and 2010: a systematic analysis for the global burden of disease study 2010 Lancet. 2012;380:2095-128.

2. Institute for Health Metrics and Evaluation. GBD compare. 2017 https://vizhub. healthdata.org/gbd-compare/. Accessed 17 July 2017.

3. Haiman CA, Chen GK, Blot WJ, Strom SS, Berndt SI, Kittles RA, et al. Characterizing genetic risk at known prostate cancer susceptibility loci in African Americans. PLoS Genet. 2011;7:e1001387.

4. Sartor A. Risk factors for prostate cancer. UpToDate. 2017. http://www. uptodate.com/contents/risk-factors-for-prostate-cancer?source=search_ result\&search=prostate+cancer+risk+factors\&selectedTitle $=1 \sim 150 \# \mathrm{H} 11$. Accessed 17 July 2017

5. Caribbean Community Secretariat. Declaration of Port-of-Spain: uniting to stop the epidemic of chronic NCDs. 2011. https://caricom.org/media-center/ communications/statements-from-caricom-meetings/declaration-of-port-ofspain-uniting-to-stop-the-epidemic-of-chronic-ncds. Accessed 18 June 2018.

6. Commission on Social Determinants of Health. Closing the gap in a generation: health inequity through action on the social determinants of health: World Health Organization; 2008. http://www.who.int/social_ determinants/final_report/csdh_finalreport_2008.pdf. Accessed 17 July 2017

7. World Health Organization. Rio political declaration on social determinants of health. 2011. http://www.who.int/sdhconference/declaration/Rio_ political_declaration.pdf?ua=1. Accessed 17 July 2017.

8. Gilligan T. Social disparities and prostate cancer: mapping the gaps in our knowledge. Cancer Causes Control. 2005;16:45-53.

9. Khan $\mathrm{H}$. Determinants of prostate cancer: the Birmingham prostatic neoplasms association study. 2011. http://etheses.bham.ac.uk/3170/1/Khan H_11_PhD.pdf. Accessed 07 July 2015.

10. Krieger N, Quesenberry C Jr, Peng T, Horn-Ross P, Stewart S, Brown S, et al. Social class, race/ethnicity, and incidence of breast, cervix, colon, lung, and prostate cancer among Asian, black, Hispanic, and white residents of the San Francisco Bay Area, 1988-92 (United States). Cancer Causes Control. 1999;10:525-37.

11. Parent M-É, Siemiatycki J. Occupation and prostate cancer. Epidemiol Rev. 2001;23:138-43.

12. Dickey SL, Cormier EM, Whyte J, Graven L, Ralston PA. Demographic, social support, and community differences in predictors of African-American and white men receiving prostate cancer screening in the United States. Public Health Nurs. 2016:33(6):483-92.

13. Guessous I, Cullati S, Fedewa SA, Burton-Jeangros C, Courvoisier DS, Manor $\mathrm{O}$, et al. Prostate cancer screening in Switzerland: 20-year trends and socioeconomic disparities. Prev Med. 2016;82:83-91.

14. Nikolaidis C, Tentes I, Lialiaris T, Constantinidis TC, Kortsaris A. Regional disparities in cancer mortality across the rural-urban axis: a case study from North-Eastern Greece. Rural Remote Health. 2015;15:3013.

15. Blas E, Kurup AS, editors. Equity, social determinants, and public health programmes: World Health Organization; 2010. http://whqlibdoc.who.int/ publications/2010/9789241563970_eng.pdf. Accessed 17 July 2017

16. Sobers-Grannum N, Murphy MM, Nielsen A, Guell C, Samuels TA, Bishop L, et al. Female gender is a social determinant of diabetes in the Caribbean: a systematic review and meta-analysis. PLoS One. 2015;10(5):e0. 126799 
17. O'Neill J, Tabish H, Welch V, Petticrew M, Pottie K, Clarke M, et al. Applying an equity lens to interventions: using PROGRESS ensures consideration of socially stratifying factors to illuminate inequities in health. J Clin Epidemiol. 2014;67:56-64.

18. International Development Research Council. Evaluating CARICOM's political commitments for non-communicable disease prevention and control: IDCR; 2015. https:/www.idrc.ca/en/project/evaluating-caricoms-political-commitmentsnon-communicable-disease-prevention-and-control. Accessed 17 July 2017

19. U.S. National Library of Medicine. Fact sheet MEDLINE, PubMed, and PMC (PubMed Central): How are they different? 2017. https://www.nlm.nih.gov/ bsd/difference.html. Accessed 18 June 2018.

20. Elsevier R\&D Solutions. Embase fact sheet. https://www.elsevier.com/_data/ assets/pdf_file/0016/59011/Embase-Academic-factsheet-Final-WEB.pdf. Accessed 18 June 2018.

21. SciELO, FAPESP, BIRME. SciELO [Internet]: SciELO; n.d. http://www.scielo.br/. Accessed 17 July 2017

22. EBSCO. CINAHL database [Internet]. 2017. https://health.ebsco.com/ products/the-cinahl-database. Accessed 17 July 2017.

23. Centro Nacional de Información de Ciencias Médicas, Infomed. Bibliographic databases. 2017. http://www.bvsite.sld.cu/php/level.php?lang=en\&component= 30\&item=3. Accessed 17 July 2017.

24. EndNote. Thomson Reuters. 2017. Available from: www.endnote.com. Accessed 17 July 2017.

25. Harris PA, Taylor R, Thielke R, Payne J, Gonzalez N, Conde J. Research electronic data capture (REDCap) - a metadata-driven methodology and workflow process for providing translational research informatics support. J Biomed Inform. 2009;42:377-81

26. von Elm E, Altman DG, Egger M, Pocock SJ, Gøtzsche PC, Vandenbroucke $J$, et al. The strengthening the reporting of observational studies in epidemiology (STROBE) statement: guidelines for reporting observational studies. J Clin Epidemiol. 2008;61:344-9.

27. Welch V, Petticrew M, Tugwell P, Moher D, O'Neill J, Waters E, et al. PRISMAequity 2012 extension: reporting guidelines for systematic reviews with a focus on health equity. PLoS Med. 2012;9:e1001333.

28. A Cochrane risk of bias assessment tool: for non-randomized studies of interventions (ACROBAT-NRSI), version 1.0.0. The Cochrane Collaboration. 2017. https://sites.google.com/site/riskofbiastool/. Accessed 18 June 2018.

29. Snilstveit B, Vojtkova M, Bhavsar A, Gaarder M. Evidence gap maps: a tool for promoting evidence-informed policy and prioritizing future research: The World Bank; 2013. Report no.: WPS6725. https://openknowledge.worldbank org/bitstream/handle/10986/16941/WPS6725.pdf. Accessed 17 July 2017

30. Fernández L, Galán Y, Jiménez R, Gutiérrez Á, Guerra M, Pereda CM, et al. Estudio de casos y controles sobre factores de riesgo de cáncer de próstata. Rev Cubana Salud Pública. 2005;31:174-81.

31. Fernández L, Galán Y, Jiménez R, Gutiérrez Á, Guerra M, Pereda C, et al. Sexual behaviour, history of sexually transmitted diseases, and the risk of prostate cancer: a case-control study in Cuba. Int J Epidemiol. 2005;34:193-7.

32. Jackson M, Tulloch-Reid M, Walker S, McFarlane-Anderson N, Bennett F, Francis $D$, et al. Dietary patterns as predictors of prostate cancer in Jamaican men. Nutr Cancer. 2013;65:367-74.

33. Nemesure B, Wu S-Y, Hennis A, Leske MC. Family history of prostate cancer in a black population. J Immigr Minor Health. 2013;15:1107-12.

34. Soto-Salgado M, Suárez E, Torres-Cintrón M, Pettaway CA, Colón V, Ortiz AP. Prostate cancer incidence and mortality among Puerto Ricans: an updated analysis comparing men in Puerto Rico with US racial/ethnic groups. P R Health Sci J. 2012;31:107-13.

35. Jackson MD, Walker SP, Simpson-Smith CM, Lindsay CM, Smith G, McFarlaneAnderson N, et al. Associations of whole-blood fatty acids and dietary intakes with prostate cancer in Jamaica. Cancer Causes Control. 2012;23:23-33.

36. McDonald AC, Jenkins FJ, Bunker CH, Wilson JW, Patrick AL, Weissfeld JL. A case-cohort study of human herpesvirus 8 seropositivity and incident prostate cancer in Tobago. Infect Agent Cancer. 2011;6:25.

37. Multigner L, Ndong JR, Giusti A, Romana M, Delacroix-Maillard H, Cordier S, et al. Chlordecone exposure and risk of prostate cancer. J Clin Oncol. 2010;28:3457-62.

38. Torres-Cintrón M, Ortiz AP, Ortiz-Ortiz KJ, Figueroa-Vallés NR, Pérez-lrizarry J, Díaz-Medina G, et al. Using a socioeconomic position index to assess disparities in cancer incidence and mortality, Puerto Rico, 1995-2004. Prev Chronic Dis. 2012;9:E15.

39. Jackson MD, Tulloch-Reid MK, Lindsay CM, Smith G, Bennett Fl, McFarlaneAnderson N, et al. Both serum 25-hydroxyvitamin D and calcium levels may increase the risk of incident prostate cancer in Caribbean men of African ancestry. Cancer Med. 2015;4:925-35.
40. Santana RS, Santana ÁLS, García ICC, Cisnero MB. Mortalidad por tumores malignos en Santiago de Cuba durante 2010. Medisan. 2011;15:1510-6.

41. Smit E, Garcia-Palmieri MR, Figueroa NR, McGee DL, Messina M, Freudenheim $J$, et al. Protein and legume intake and prostate cancer mortality in Puerto Rican men. Nutr Cancer. 2007;58:146-52.

42. Bray F, Piñeros M. Cancer patterns, trends and projections in Latin America and the Caribbean: a global context. Salud Publica Mex. 2016;58:104-17.

43. Anderson NB, Bulatao RA, Cohen B, editors. Critical perspectives on racial and ethnic differences in health in late life: National Research Council (US) Panel on Race, Ethnicity, and Health in Later Life; 2004. http://www.ncbi. nlm.nih.gov/books/NBK25532/. Accessed 17 July 2017

44. Baade PD, Yu XQ, Smith DP, Dunn J, Chambers SK. Geographic disparities in prostate cancer outcomes-review of international patterns. Asian Pac J Cancer Prev. 2015;16:1259-75.

45. Cheng I, Witte JS, McClure LA, Shema SJ, Cockburn MG, John EM, et al. Socioeconomic status and prostate cancer incidence and mortality rates among the diverse population of California. Cancer Causes Control. 2009;20: 1431-40.

46. Merletti F, Galassi C, Spadea T. The socioeconomic determinants of cancer. Environ Health. 2011;10:S7.

47. Kangmennaang J, Luginaah I. The influences of health insurance and access to information on prostate Cancer screening among men in Dominican Republic J Cancer Epidemiol. 2016; https://doi.org/10.1155/2016/7284303. Accessed 17 July 2017.

48. La Vecchia C, Franceschi S, Talamini R, Negri E, Boyle P, D’Avanzo B. Marital status, indicators of sexual activity and prostatic cancer. J Epidemiol Community Health. 1993;47:450-3.

49. Newell GR, Pollack ES, Spitz MR, Sider JG, Fueger JJ. Incidence of prostate cancer and marital status. J Natl Cancer Inst. 1987;79:259-62.

50. Blumberg S, Vahratian A, Blumberg J. Marriage, cohabitation, and men's use of preventive health care services: NCHS Data Brief; 2014. http://www.cdc. gov/nchs/data/databriefs/db154.pdf. Accessed 17 July 2017

51. Dean LT, Subramanian SV, Williams DR, Armstrong K, Charles CZ, Kawachi I. Getting black men to undergo prostate cancer screening the role of social capital. Am J Mens Health. 2014;9:385-96.

52. Rosenblatt KA, Wicklund KG, Stanford JL. Sexual factors and the risk of prostate Cancer. Am J Epidemiol. 2001;153:1152-8.

53. Dennis LK, Dawson DV. Meta-analysis of measures of sexual activity and prostate cancer. Epidemiology. 2002;13:72-9.

54. Lian W-Q, Luo F, Song X-L, Lu Y-J, Zhao S-C. Gonorrhea and prostate cancer incidence: an updated meta-analysis of 21 epidemiologic studies. Med Sci Monit. 2015:21:1895-903.

55. Bae J-M. Human papillomavirus 16 infection as a potential risk factor for prostate cancer: an adaptive meta-analysis. Epidemiol Health. 2015;17:e2015005.

56. Tyson MD, Andrews PE, Etzioni DA, Ferrigni RG, Humphreys MR, Swanson SK, et al. Marital status and prostate cancer outcomes. Can J Urol. 2013;20:6702-6.

57. Evans S, Metcalfe C, Ibrahim F, Persad R, Ben-Shlomo Y. Investigating blackwhite differences in prostate cancer prognosis: a systematic review and meta-analysis. Int J Cancer. 2008;123:430-5.

58. Keshava C, McCanlies EC, Weston A. CYP3A4 polymorphisms-potential risk factors for breast and prostate cancer: a HuGE review. Am J Epidemiol. 2004;160:825-41.

59. Zeigler-Johnson CM, Walker AH, Mancke B, Spangler E, Jalloh M, McBride S, et al. Ethnic differences in the frequency of prostate cancer susceptibility alleles at SRD5A2 and CYP3A4. Hum Hered. 2002;54:13-21.

60. Hambleton IR, Howitt C, Jeyaseelan S, Murphy MM, Hennis AJ, Wilks R, et al. Trends in longevity in the Americas: disparities in life expectancy in women and men, 1965-2010. PLoS One. 2015;10:e0129778.

61. Torres R, Santos E, Orraca L, Elias A, Palacios C. Diet quality, social determinants, and weight status in Puerto Rican children aged 12 years. J Acad Nutr Diet. 2014;114:1230-5.

62. Stony Brook University Medical Center. Prostate Cancer in a Black Population. Stony Brook Med. 2009. https://medicine.stonybrookmedicine. edu/prevmed/research/grants/pcbp. Accessed 18 June 2018.

63. National Heart, Lung, and Blood Institute. Puerto Rico Heart Health Program (PRHHP) Natl. Inst. Health. 2008. https://biolincc.nhlbi.nih.gov/studies/prhhp/. Accessed 17 July 2017

64. Bunker CH, Patrick AL, Konety BR, Dhir R, Brufsky AM, Vivas CA, et al. High prevalence of screening-detected prostate cancer among Afro-Caribbeans: the Tobago Prostate Cancer Survey. Cancer Epidemiol Biomarkers Prev. 2002;11:726-9. 